This item was submitted to Loughborough's Research Repository by the author.

Items in Figshare are protected by copyright, with all rights reserved, unless otherwise indicated.

\title{
Modelling the impact of land subsidence on urban pluvial flooding: a case study of downtown Shanghai, China.
}

PLEASE CITE THE PUBLISHED VERSION

http://dx.doi.org/10.1016/j.scitotenv.2015.11.159

\section{PUBLISHER}

(C) Elsevier

VERSION

AM (Accepted Manuscript)

\section{PUBLISHER STATEMENT}

This work is made available according to the conditions of the Creative Commons Attribution-NonCommercialNoDerivatives 4.0 International (CC BY-NC-ND 4.0) licence. Full details of this licence are available at: https://creativecommons.org/licenses/by-nc-nd/4.0/

\section{LICENCE}

CC BY-NC-ND 4.0

\section{REPOSITORY RECORD}

Yin, Jie, Dapeng Yu, and Robert L. Wilby. 2019. "Modelling the Impact of Land Subsidence on Urban Pluvial Flooding: A Case Study of Downtown Shanghai, China.". figshare. https://hdl.handle.net/2134/19983. 


\title{
Modelling the impact of land subsidence on urban pluvial flooding: a case study of downtown Shanghai, China
}

\author{
Jie Yin ${ }^{1 *}$, Dapeng $\mathrm{Yu}^{2}$, Rob Wilby ${ }^{2}$ \\ 1 School of Geographical Sciences, East China Normal University, China \\ 2 Centre for Hydrological and Ecosystem Science, Department of Geography, Loughborough University, UK
}

\begin{abstract}
This paper presents a numerical analysis of pluvial flooding to evaluate the impact of land subsidence on flood risks in urban contexts using a hydraulic model (FloodMap-HydroInundation2D). The pluvial flood event of August 2011 in Shanghai, China is used for model calibration and simulation. Evolving patterns of inundation (area and depth) are assessed over four time periods (1991, 1996, 2001 and 2011) for the downtown area, given local changes in topography and rates of land subsidence of up to $27 \mathrm{~mm} / \mathrm{yr}$. The results show that land subsidence can lead to non-linear response of flood characteristics. However, the impact on flood depths is generally minor $(<5 \mathrm{~cm})$ and limited to areas with lowest-lying topographies because of relatively uniform patterns of subsidence and micro-topographic variations at the local scale. Nonetheless, the modelling approach tested here may be applied to other cities where there are more marked rates of subsidence and/or greater heterogeneity in the depressed urban surface. In these cases, any identified hot-spots of subsidence and focusing of pluvial flooding may be targeted for adaptation interventions.
\end{abstract}

Keywords: Land subsidence; Urban pluvial flooding; FloodMap; Shanghai; Adaptation

\section{Introduction}

Pluvial flooding is one of the most common natural hazards in many parts of the world and is attracting growing public concern. This coincides with an intensified hydrologic cycle associated with climate variability and change, combined with rapid urbanization (IPCC 2007a; Du et al. 2012; Suriya and Mudgal 2012; Zhou et al. 2012; Wu et al., 2013). There 
are both direct impacts (e.g. personal injury and property damage) and indirect consequences (e.g. interruption to public services), particularly in many cities worldwide where rapid urban has growth outpaced the capacity of storm sewer drainage. For example, a pluvial flood event in Beijing in July 2011 led to 79 deaths and damages of $\$ 1.86$ billion. Critical infrastructure such as traffic and power systems and residents' livelihoods were seriously affected (Yin et al. 2015a). Pluvial flooding is increasingly being reported in developed countries. For example, a government commissioned report found that the majority of the damages caused by the 2007 floods in the UK were due to overloaded storm sewer systems in developed areas (Pitt 2008). Indeed, pluvial flooding appears to be increasing in many parts of the world (e.g. Wu et al. 2013) and it is receiving increased media coverage and policy attention.

Localized factors such as land subsidence may also play a role in urban pluvial flooding. However, the spatial-temporal effect of land subsidence on pluvial flood risks has not been fully understood. Widespread occurrence of land subsidence caused by natural processes (e.g. tectonic activities) and/or anthropogenic activities (e.g. extraction of oil, gas and groundwater) has been reported in many urban environments (e.g. Waltham 2002, Marfai and King 2008, Brown and Nicholls, 2015). Land subsidence is recognized as a chronic hazard affecting urban flooding, especially in coastal/delta megacities such as Tokyo, Osaka, Shanghai, Taipei, Bangkok, Jakarta, Manila and New Orleans (Dixon et al. 2006; IPCC 2007b; Syvitski et al. 2009; Jago-on et al. 2009). The underlying impacts of land subsidence on urban pluvial flood can be seen in the form of changes in runoff and flow patterns locally on the land surface. Hence, it is important to evaluate pluvial flood hazard by taking into account the temporal variations of urban topography induced by land subsidence.

There is a general awareness that sinking land may be responsible for increasing pluvial flood risk in subsidence prone cities (e.g. Chan et al. 2012). However, few studies have numerically investigated the relationship between land subsidence and pluvial flooding in complex urban communities, largely due to the lack of high accuracy and 
multi-temporal topographic data. However, the advent of Light Detection And Ranging (LiDAR) techniques (i.e. airborne and terrestrial laser scanners), combined with the geodetic techniques (e.g. levelling surveys, GPS surveys, and InSAR technique) (e.g. Abidin 2005; Cabral-Cano et al. 2008; Osmanoglu et al. 2011; Yan et al. 2012), and advances in high resolution flood modelling techniques (Sampson et al. 2012) have enabled the numerical modelling of dynamic urban pluvial flood risks in the context of land subsidence.

In this study, we explore the role of land subsidence in modulating pluvial flooding within an urban centre. Downtown Shanghai is used as a case study because the area is prone to flooding from pluvial sources and has been experiencing significant long-term land subsidence. We begin by analyzing the spatio-temporal characteristics of urban pluvial flooding corresponding to historical land subsidence occurrences. We then interpret probable mechanisms controlling the flood patterns. Section 2 describes the materials and methods, including the study site, data availability, model description, model construction and evaluation metrics; Section 3 presents the results and discussion. The conclusions and some suggestions for further research are given in Section 4.

\section{Materials and methods}

\subsection{Study site}

The watershed selected lies in the central Shanghai metropolitan area (the North Huangpu District), bordering the Huangpu River to the east and Suzhou Creek to the north (Fig. 1). The watershed is a closed system with two elevated highways on the western (South-North Elevated Highway) and southern (Yan'an Elevated Highway) boundaries. The floodwalls along the rivers, combined with the elevated highways act as barriers to flow. As such, no water exchange occurs across the boundary. The area is $\sim 3.25 \mathrm{~km}^{2}$ and has low-lying topography with an average altitude of about $3 \mathrm{~m}$ above Wusong Datum. The region experiences a northern subtropical monsoon climate and receives annual precipitation of $\sim 1,100 \mathrm{~mm}$. Heavy and extreme rainfalls frequently hit this region during the flood season (June to September) due to 
the city's location in the path of tropical cyclones (Yin and Zhang 2015).

The study area has been the downtown part of Shanghai since the mid to late nineteenth century. It therefore comprises a typical urban landscape with dense buildings, heavy traffic, impermeable surfaces, and few open green spaces (such as the People's Park, Figure 1). Storm drainage in the form of pumps and sewer systems is the only way to take excess storm water from the site. The drainage capacity was generally designed to cope only with a 1 in 1 year rainfall $(36 \mathrm{~mm} / \mathrm{h})$ after the 1990s. The drainage system for the central business district (CBD) has been improved to withstand a 1 in 3 year rainfall $(49.6 \mathrm{~mm} / \mathrm{h})$ since 2002.

Land subsidence has been surveyed in central Shanghai through a combination of levelling (since the 1920s) and GPS (since the 1990s). Long term subsidence is due to: (i) relatively constant rates of tectonic subsidence (1 mm/year); and (ii) non-uniform compaction of sediments (more than $20 \mathrm{~mm} /$ year on average between 1921 and 2007) due to groundwater withdrawal, construction of high-rise buildings, and underground engineering (Yin et al. 2013). In some areas, cumulative subsidence levels have exceeded $3 \mathrm{~m}$ since the 1920s and changed the urban topography remarkably, thereby increasing local vulnerability to pluvial flooding (Xu et al. 2008).

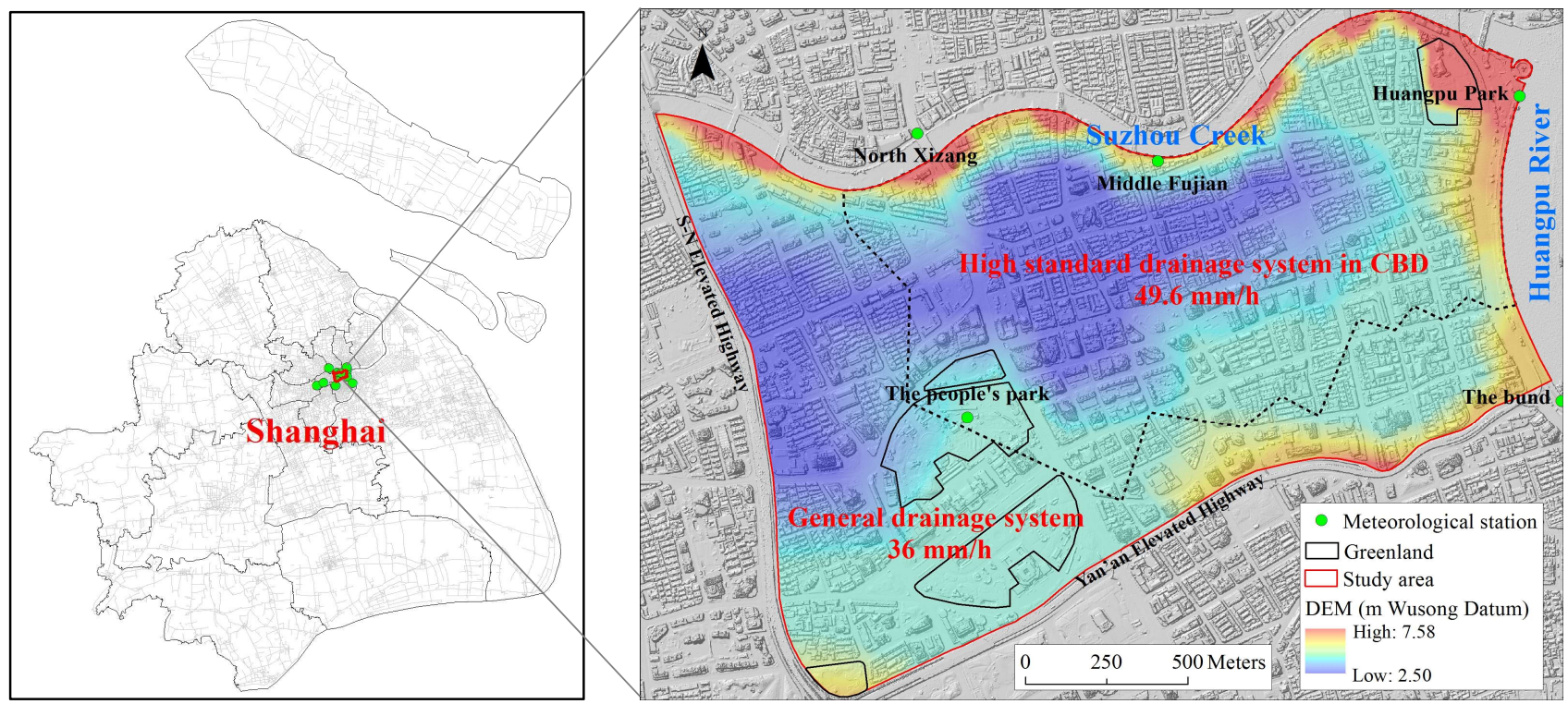

Fig. 1 Location of the study area, the black dot line divides the area into two parts (i.e. higher standard drainage 
area-CBD and general drainage area).

\subsection{Data availability}

\subsubsection{Precipitation data}

15-minute precipitation totals were obtained for 12 meteorological stations distributed across the study area and adjacent regions, for the 12 August 2011 event (a typical summer storm). Distributed precipitation amounts for each time slice were interpolated via ordinary kriging between stations (Fig. 2). The event began around 8:00 am and lasted less than 4 hours, with more than $90 \%$ of the rainfall concentrated in the first 45 minutes. The maximum intensity centred initially on the southwest and moved to the northeast shortly afterwards ( 8:15am). Rainfall accumulation rates of $70-80 \mathrm{~mm} / \mathrm{hr}$ were reported. This corresponds to a $\sim 30$-year return period and overwhelmed the local drainage system. Subsequent surface flooding of streets and properties then caused considerable damage and traffic disruption in the morning rush hour.

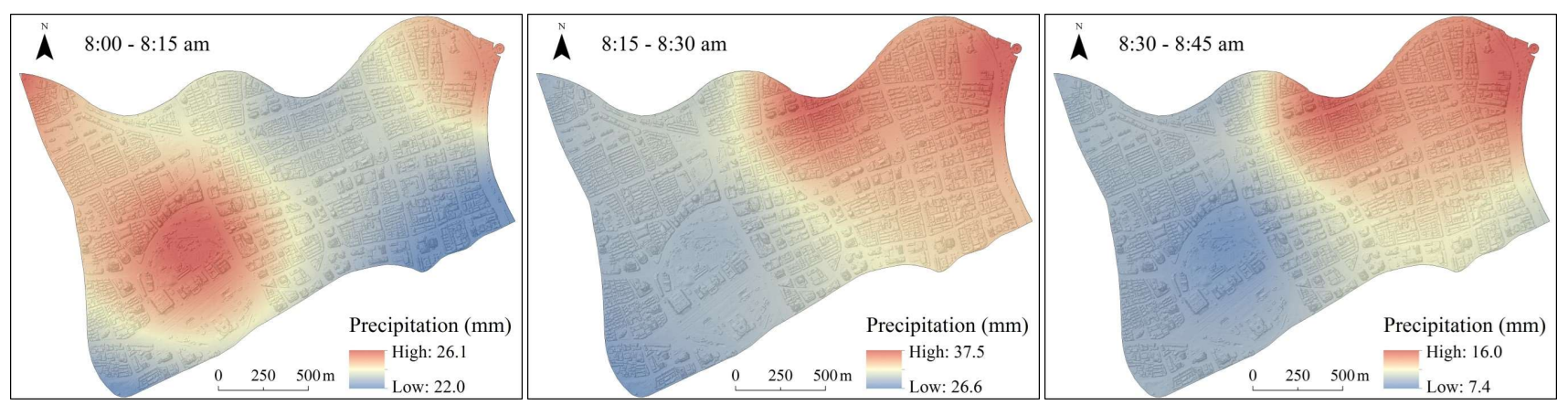

Fig. 2 Spatial and temporal distribution of precipitation during the 12 August 2011 flood in Shanghai.

\subsubsection{Topography and subsidence data}

Availability of a recent high resolution topographic dataset and multi-temporal land subsidence rates allowed us to reconstruct the historical elevations at multiple points in time. Airborne LiDAR data of the study area in 2006 (with an average image separation of $0.6 \mathrm{~m}$ ) was provided by the Shanghai Survey Bureau. The original LiDAR dataset is quality-controlled and segmented using TerraSolid software. A Digital Elevation Model (DEM) was produced with non-topographic features (e.g. trees, cars and buildings) removed using classification algorithms in the TerraScan module 
(Feng et al. 2007). The resulting surface points were aggregated into a raster Digital Terrain Model (DTM) with resolution $2 \mathrm{~m}$. Vertical accuracy of the data is estimated to be $\pm 10 \sim 20 \mathrm{~cm}$, commensurate with the typical accuracy associated with LiDAR data (Feng et al. 2007). Furthermore, building heights are re-built into the DTM to account for blockage effects.

Land subsidence contours (http://www.sigs.com.cn/sigsonlines/) were generated from thousands of subsidence monitoring points (e.g. levelling points, GPS, CCD hydrostatic levelling system and 4675 Liquid Level Sensors) throughout Shanghai during 1991-1995, 1996-2000, 2001-2005 and 2006-2010 provided by the Shanghai Institute of Geological Survey. These data were interpolated to produce land subsidence surfaces with $2 \mathrm{~m}$ resolution. Urban topographies for 1991, 1996, 2001 and 2011 were generated using arithmetic subtractions and/or summation of the 2006 DSM and four distributed subsidence maps under the assumption that the area is fully developed and therefore no significant changes apart from land subsidence impacts will change the ground elevation. These data have been used in previous research on flood risks in the city (e.g. Yin et al. 2015b).

\subsubsection{Observed inundation data}

Although downtown Shanghai is prone to pluvial flooding, there are no aerial images or field surveys of flood extent for the study event. However, discrete point-based flood information does exist in two other forms: 1) water depths from electronic gauges operated by the Shanghai Water Authority and typically installed at traffic hotspots of pluvial flooding; 2) flood incidents reported by the public ("crowd source") through the web engines (e.g. Google and Baidu) and an online official emergency incident reporting portal (http://222.66.79.122/BMXX/default.htm?GroupName=灾情快报). Two of the five monitoring points in the study area reported inundation for this particular flood event, but the time series measurements are incomplete and unreliable, so they were not used in this study. Crowd sourced data provide extensive information, including the location of the property/road affected, a description of its nature and in a limited cases, an 
empirical estimate of inundation depth. However, there are inherent uncertainties in the reported incidents in terms of location and timing. Using historical records, we found that the timing and magnitude of a crowd-sourced incident are most uncertain and in many cases incomplete. For all records, the time when an incident is reported is recorded and only in very limited cases the actual time of flood occurrence is submitted. Similarly, the magnitude is rarely reported and can be highly unreliable. The location component associated with a crowd-sourced data point is often comparably more reliable. Most incidents have an associated house number or business address, although many lack a precise location apart from a brief description of the flood site, making them difficult to geo-locate at a street resolution. With the improvement of geo-referencing in online map providers such as Google and Baidu, we are able to pinpoint 17 incidents where locations are confidently identified.

\subsection{Model description}

To derive pluvial flood risks associated with different urban landscapes associated with land subsidence, we use the hydro-inundation model (FloodMap-HydroInundation2D) (Yu and Coulthard 2015). Here we present the major structure of the model. The model couples hydrological processes with flood inundation for high-resolution pluvial (surface water) flood modelling in urban environments. Surface flow routing takes the same structure as the inertial model of Bates et al. (2010), but with a slightly different approach to the calculation of time step. Rather than using a global Courant-Freidrich-Levy Condition where the time step for the next iteration is calculated based on the maximum water depth and velocity found at the last time step (e.g. Bates and De Roo 2000; Yu and Lane 2006a), the Forward Courant-Freidrich-Levy Condition (FCFL) approach described in Yu and Lane (2011) for the diffusion-based version of FloodMap is used in the model to calculate time step. Assuming slow moving flow when the convective acceleration term in the Saint-Venant equation can be neglected, the momentum equation becomes: 
$\frac{\partial q}{\partial t}+\frac{g h \partial(h+z)}{\partial x}+\frac{g n^{2} q^{2}}{R^{4 / 3} h}=0$

Where $q$ is the flow per unit width, $g$ is the acceleration due to gravity, $R$ is the hydraulic radius, $z$ is the bed elevation, $h$ is the water depth and $n$ is the Manning's roughness coefficient. Discretizing the equation with respect to time produces:

$\frac{q_{t+\Delta t}-q_{t}}{\Delta t}+\frac{g h_{t} \partial(h+z)}{\partial x}+\frac{g n^{2} q_{t}^{2}}{h_{t}^{7 / 3}}=0$

To further improve this, $q_{t}$ in the friction term can be replaced by $q_{t+\Delta t}$ giving explicit expression of flow at the next time step:

$q_{t+\Delta t}=\frac{q_{t}-g h_{t} \Delta t\left(\frac{\Delta\left(h_{t}+z\right)}{\Delta x}\right)}{\left(1+g h_{t} \Delta t n^{2} q_{t} / h_{t}^{10 / 3}\right)}$

Flows in the $\mathrm{x}$ and $\mathrm{y}$ directions are decoupled and take the same form. Flow is evaluated at cell edges, depth at the centre.

Infiltration over saturation is represented by the widely used Green-Ampt equation, which approximates the rate of infiltration as a function of the capillary potential, porosity, hydraulic conductivity and time, taking the following form:

$f(t)=K_{s}\left(\frac{\varphi_{f}+h_{o}}{z_{f}}+1\right)$

Where $K_{S}$ is the hydraulic conductivity of the soil at field saturation, $\varphi_{f}$ is the capillary potential across the wetting front, $h_{o}$ is the ponding water on the soil surface, and $z_{f}$ is cumulative depth of infiltration. Hydraulic conductivity is often used as a calibration parameter in hydrological studies but for an urban environment like Shanghai, this is not defensible because of the largely impervious nature of the landscape (see section 2.4 for further details).

Evapotranspiration is calculated using a simple seasonal sine curve for daily potential evapotranspiration (Calder et al. 1983) with the equation below:

$E_{p}=\overline{E_{p}}\left[1+\sin \left(\frac{360 i}{365}-90\right)\right]$

Where $\overline{E_{p}}$ is the mean daily potential evapotranspiration and $i$ is the day of the year. The amount of mass loss to evapotranspiration is typically limited due to the short duration of urban pluvial flooding. 
To account for urban storm drainage capacity, mass loss to the storm sewer system is considered in the model using the design capacity, which corresponds to a rainfall event of certain intensity $(\mathrm{mm} / \mathrm{h})$ and return period. If the model is applied to an extreme event (defined here as a $>1$ in 100 year), it is reasonable to assume that the storm sewer system drains water away at the maximum design capacity. For each time step, the amount of runoff loss to the urban storm sewer system is calculated by scaling the drainage capacity ( $\mathrm{mm} /$ hour) for the time step. Distributed drainage capacity can also be incorporated into the model on a cell by cell basis. Note that manholes and drains were not explicitly represented by the model (as in Liu et al. 2014). Rather, the drainage capacity is considered an aggregate volume that equates to the design capacity throughout that whole area.

\subsection{Simulation design and model calibration}

In order to quantify the impact of land subsidence on urban pluvial flooding, simulations were performed by considering urban terrain changes only, assuming that other factors (e.g. drainage capacity) remain constant from 1991 to 2011. Calibration and validation were performed by comparing model prediction with observed data of 12 August 2011 pluvial flood event presented in Section 2.2.3. Drainage capacity used in calibration takes a uniform value of $36 \mathrm{~mm} / \mathrm{h}$. The calibrated FloodMap-Inundation model was then run using 1991, 1996, 2001, 2006 and 2011 urban topographies for a four hour simulation (8:00 to 12:00) of the event.

A $2 \mathrm{~m}$ DEM was used to represent the urban topography, with building blocks re-built into the digital terrain model derived from LiDAR, where heights associated with vegetation and buildings were originally removed. This essentially allows the blocking effect of urban features to be represented explicitly in the modelling. This is also related to the specification of a high roughness value (see below). A coarser mesh of $4 \mathrm{~m}$ was attempted but the results were much degraded due to the inadequate representation of micro-topography. Yu and Coulthard (2015) evaluated the sensitivity to mesh resolution in a much larger domain with a mixture of urban and rural features. Given the focus of the present study, 
a $2 \mathrm{~m}$ resolution simulation was regarded as a legitimate trade-off between computational demand and simulation detail.

Evapotranspiration is specified at $3 \mathrm{~mm} /$ day, a value that can be neglected for short-duration intense rainfall in urban environment ( $\mathrm{Yu}$ and Coulthard 2015). Roughness and hydraulic conductivity are key parameters for model calibration. An initial screening was undertaken to constrain the possible range of values for these two parameters in simulating this particular flood event. A hydraulic conductivity $\left(K_{s}\right)$ value between $0.001 \mathrm{~m} / \mathrm{h}$ and $0.003 \mathrm{~m} / \mathrm{h}$ was found to yield skill when the model results were qualitatively compared with reported flood incidents and monitoring points. Given the urbanized nature of the study area, a hydraulic conductivity value of $0.001 \mathrm{~m} / \mathrm{h}$ was used in the remaining simulations.

Model sensitivity to roughness parameterization was evaluated by varying the Manning's $n$ value (between 0.01 and 0.1 at 0.01 increments), whilst maintaining hydraulic conductivity at $0.001 \mathrm{~m} / \mathrm{h}$. Consistent with Yu and Coulthard (2015), the model was found to be relatively insensitive to roughness specification for this simulation. A relatively high roughness value of 0.06 was used in the simulations, reflecting the effect of urban features (e.g. buildings) on flow routing. The default drainage capacity of the urban areas was assumed to be $36 \mathrm{~mm} /$ hour. We recognize this is likely to be a simplification considering the rapid development of the downtown area between 1991 and 2006. However, to focus on the effect of land subsidence alone, we deliberately keep this simplification in our simulations.

\subsection{Inundation change detection}

Two standard metrics were used to quantify spatio-temporal changes in flood inundation between simulations. These were the Fit statistic (F) and Root Mean Square Deviation (RMSD). In each case, the 1991 run was used as the reference simulation and both measures were calculated against this baseline. The F statistic is particularly suitable for the comparison of inundation extents as it focuses on how the simulated wet areas agree with the reference (Bates and De Roo 2000; Horritt and Bates 2001). The statistic was calculated as follow: 
$F=\frac{A_{o}}{A_{r}+A_{s}-A_{o}}$

where $A_{r}$ is the referenced wet areas, $A_{s}$ is the simulated wet areas, and $A_{o}$ is the overlapped wet areas of $A_{r}$ and $A_{s}$. The $\mathrm{F}$ statistic varies between 1 for a perfect fit and 0 when no overlapped inundation area exists.

The RMSD is widely used for assessing difference on average in water depths between two paired simulations, on a cell by cell basis (Yu and Lane 2011). It can be defined as:

$\operatorname{RMSD}=\sqrt{\frac{\sum_{i=0}^{n}\left(d_{i}^{s}-d_{i}^{r}\right)^{2}}{n}}$

where $d_{i}^{s}$ and $d_{i}^{r}$ are the simulated and referenced water depths respectively, $i$ is the index of the wet cells and $n$ is the total number of wet cells in the prediction and observation.

\section{Results and discussion}

\subsection{Model simulations for the August 2011 pluvial flood event}

The time evolution of precipitation at Huangpu Park and propagation of predicted inundation for the 12 August 2011 event are presented in Fig. 3 and Fig. 4, respectively. During the first 15 minutes of the simulation, water depths are shallow and flow routes along roadside curbs. Given the low relief, extensive surface flooding occurs from 8:30 am throughout the road network, mostly with water depth greater than $10 \mathrm{~cm}$. Maximum inundation extent $(\sim 10 \%$ of the downtown area) and depths are reached shortly after the peak rainfall at 9:00 am. As the simulation progresses storm water is funnelled towards low-lying areas where water depth exceeds $30 \mathrm{~cm}$ in some places. Thereafter, as the rainfall subsides, flood water gradually recedes due to storm sewer drainage, evapotranspiration and infiltration. 


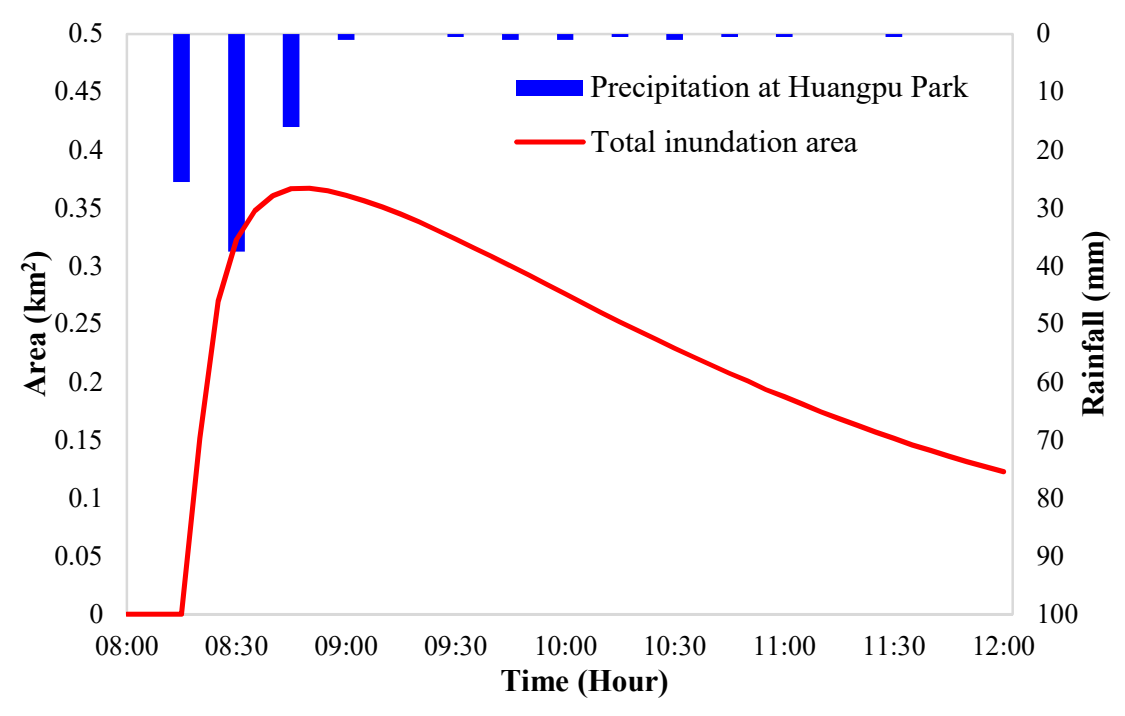

Fig.3 Precipitation at Huangpu Park and predicted total inundation area over time (baseline simulation).

Predicted maximum inundation depth and monitored/reported flood locations across the study area during the event were used to evaluate the model simulation (Fig. 5). There is a good match between the simulated inundation and observed flood incidents, especially in terms of the prediction of severely inundated areas where water depth exceeds $20 \mathrm{~cm}$. All of the 17 flooded points fall within the predicted flood areas with a water depth greater than $10 \mathrm{~cm}$, and the majority exceed $20 \mathrm{~cm}$. This agrees well with the reported estimates. However, the flood extent and depth in the southwest part of the domain appear to be overestimated as there were no reported incidents for this area.

\subsection{Subsidence effect on maximum inundation}

The spatial difference in maximum water depth between the 1991 reference simulation and subsequent years (i.e. 1996, 2001 and 2011) are shown in Fig. 6, alongside land subsidence maps for the corresponding periods. Overall, the spatial distribution of water depth changes are characterized by a high degree of consistency among the four scenarios. However, results show that land subsidence may lead to non-linear impacts on the spatial distribution of inundation. The impact is controlled by both site-scale (watershed) distribution of subsidence and micro-topographic variations at the local scale.

First, the overall pattern of flooding response is the accentuation of pluvial flooding at the subsidence centre (i.e. the 
central part of the study site in Fig. 6) and alleviation in adjacent areas. However, due to the non-linear rates of change and non-uniform patterns of subsidence between different time slices, the change in flooding is also non-uniform. For example, the funnel area at the road junctions has increased flooding between 1991-1995 and 1996-2000. The risk is decreased between 2000-2005 and increased again between 2005-2010.

This observation points to the second controlling factor, namely micro-topography at the local scale. For instance, Fig. 5 shows that water depth in the funnel areas tends to be deeper, due to flow routing from constituent roads. Where positive subsidence slopes towards crossroads, flooding tends to be aggravated at the receiving sites, and vice versa for the adjacent roads. Therefore, existing local topographic characteristics and subsequent relative land subsidence play an important role in either exacerbating or reducing water depth changes over time.

In addition, areas with significant difference in water depth tend to be associated with more intense rainfall. On the contrary, in the relatively flat region to the southwest where large open spaces are present and less rainfall in total is recorded, free flow routing occurs to a less degree and ponding in the local surface is the typical outcome. 

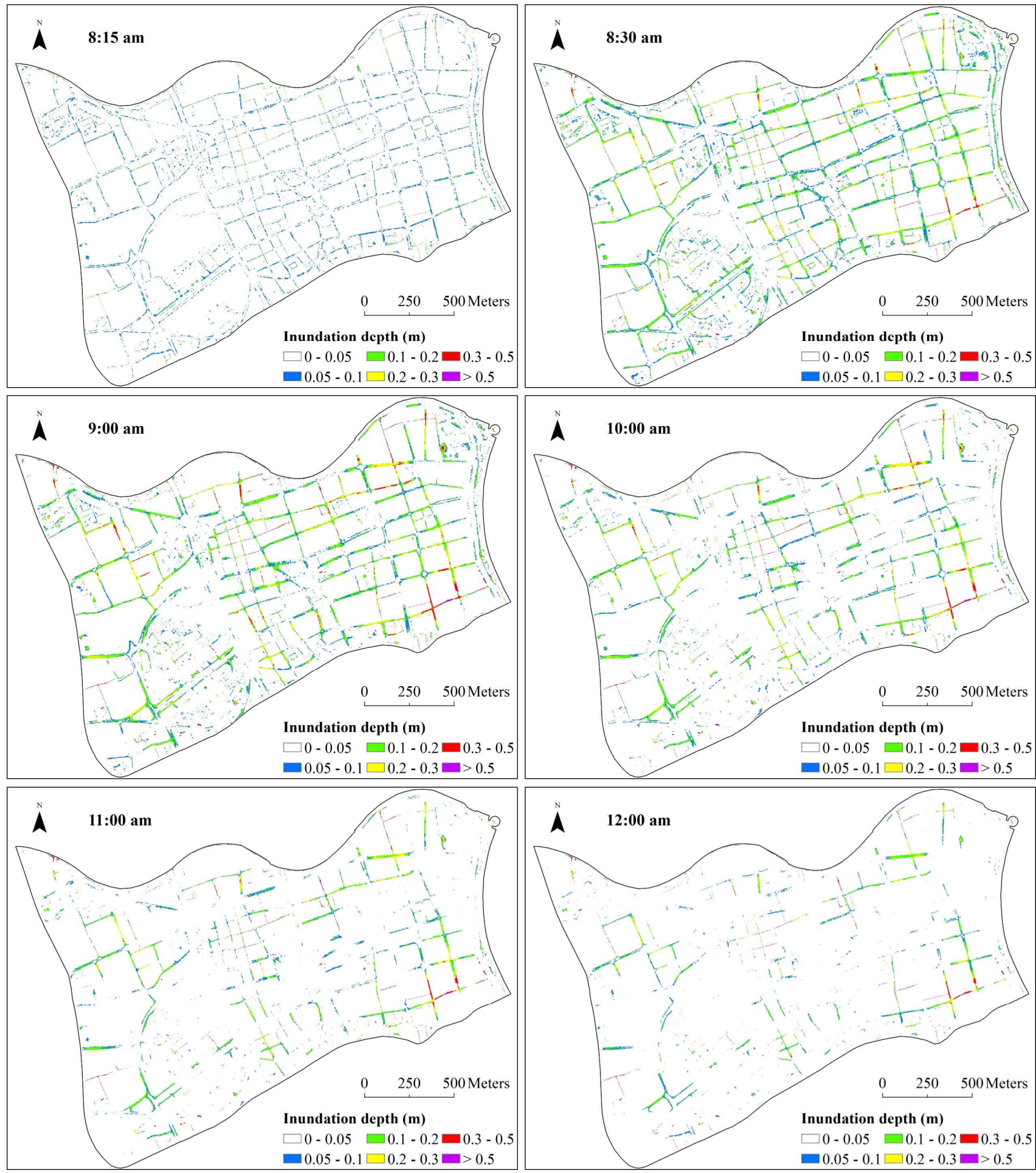

Fig.4 Time series of predicted inundation depth for the August 2011 pluvial flood event. 


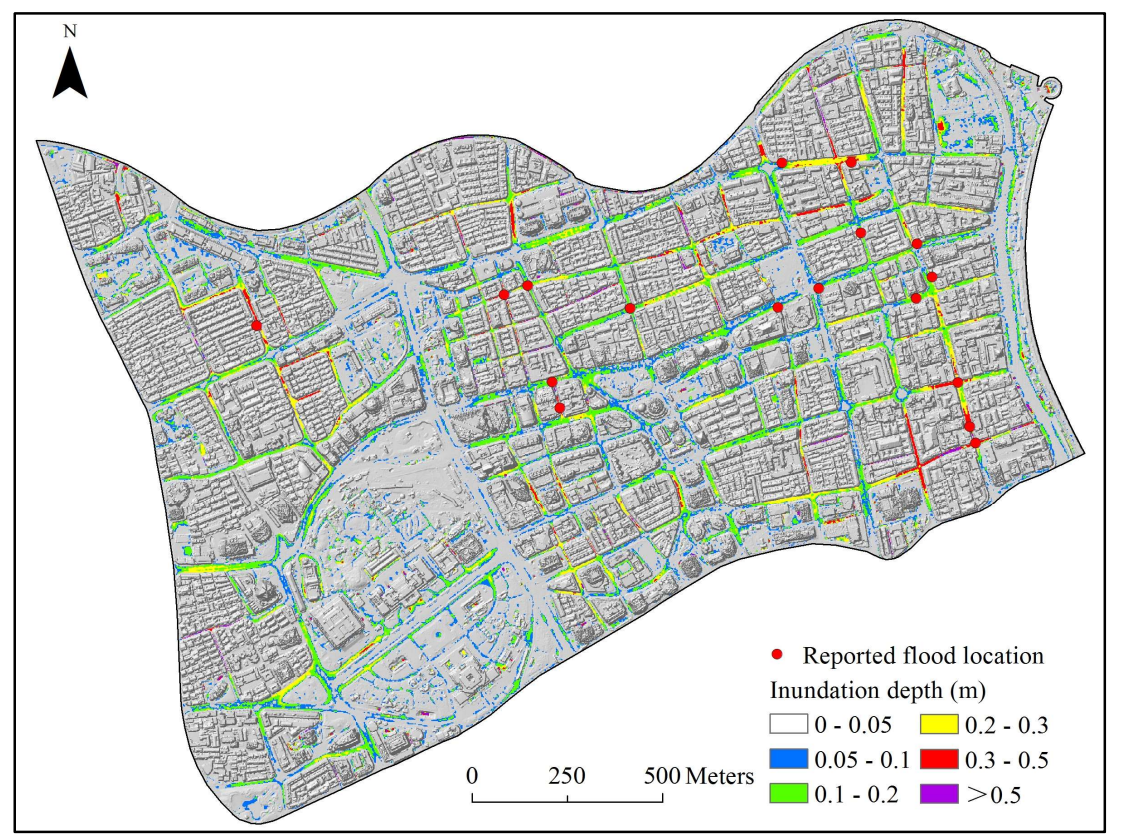

Fig.5 Predicted maximum inundation depth overlain with monitored/reported flooding during the event.

To further investigate model simulations at the local scale, a $300 \mathrm{~m}$ road section (within the black box shown in Fig. 6) was used to explore in more detail the interplay between topographic changes and flood response. Profiles of the ground elevation and maximum water depth (MWD) associated with each simulation along the road transect are shown in Fig. 7. The road surface profile appears to be high and steep at both ends but low-lying and slightly sloping to the east in the middle section. As expected, the profiles of surface elevation on different DSMs show significant negative correlations $(r$ $=-0.9$ ) with corresponding profiles of MWDs. This leads to the conclusion that local flood response to land subsidence is a function of the relative relief to surrounding area rather than the absolute magnitude of change in ground level. It is worth noting that as land subsidence developed, the west section of road experienced more rapid subsidence from 1991 to 2001, tilting the road elevation towards a more symmetrical slope profile. As a result, the corresponding MWDs increase proportionally to the west and the east section becomes correspondingly shallower. By contrast, differences in the simulated MWDs after 2001 are indiscernible because of the almost parallel surface profiles induced by largely uniform rate of land subsidence along the road, making pluvial flood less sensitive to decreases in road surface elevation. 
The inundation area and percentage change in water depth are summarized in Table 1 for each period. Overall, the impact of land subsidence on urban pluvial flooding is minor for this study, in terms of both the inundated area and depth. Results also reveal that the change in inundation depth is significantly less (about 10\%) than the magnitude of land subsidence at the same location. For approximately $94 \%$ of the total area the relatively low rate of land subsidence exhibits no obvious difference $(-1 \sim 1 \mathrm{~cm})$ in water depth in all the scenarios. The areas with increased water depth $(>1$ $\mathrm{cm})$ only account for around $2 \%$ of the total. Areas with decreasing water depth $(<-1 \mathrm{~cm})$ make up the remaining $4 \%$, indicating that the beneficial impact of land subsidence is greater. With long-term land subsidence, there has been an overall increase in areas associated with water depth changes except in the 2011 simulation which shows a slight reduction for some road sections. The overall pattern of change is controlled by the watershed-scale subsidence characteristics. However, the impact can be site-specific and determined by the complex interplay among subsidence magnitudes, micro-topographic characteristics and the intensity of precipitation at the local scale. As the city changed drastically in the last few hundred years (Wei et al. 2010), compared to the rapid development stage (up to $1.69 \mathrm{~m}$ on average for urban area) from 1921 to 1965, land subsidence during the past 20 years (1991-2010) was controlled at a relatively low degree with stricter measures (e.g. reducing groundwater exploitation, artificially recharging and adjusting the exploitation aquifers), thus making it less vulnerable to pluvial flooding. 

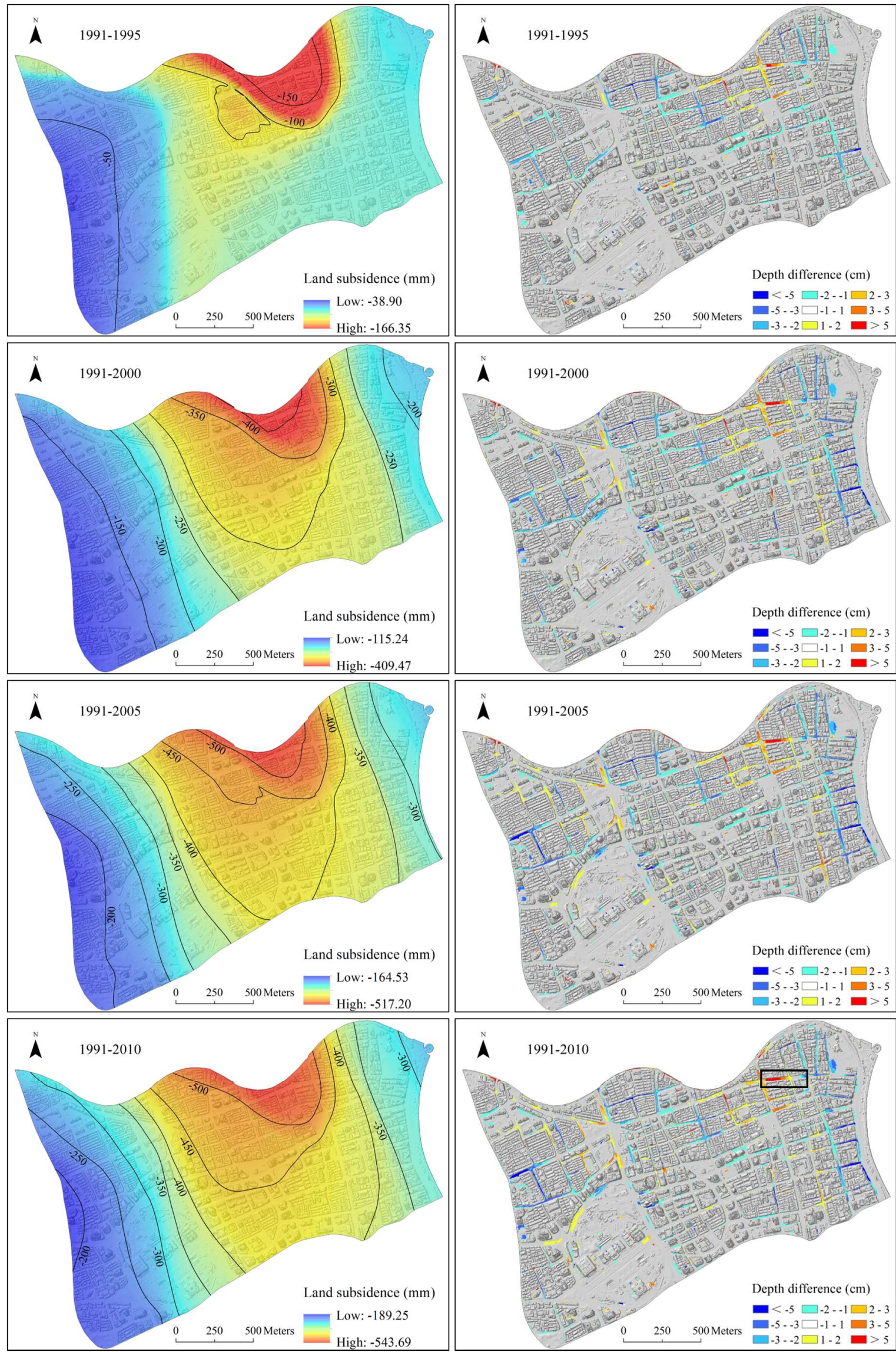

Fig.6 Accumulated land subsidence rate (left column) and change in maximum inundation depth (right column). Black box is where road elevation and water depth profiles are plotted in fig. 7. 


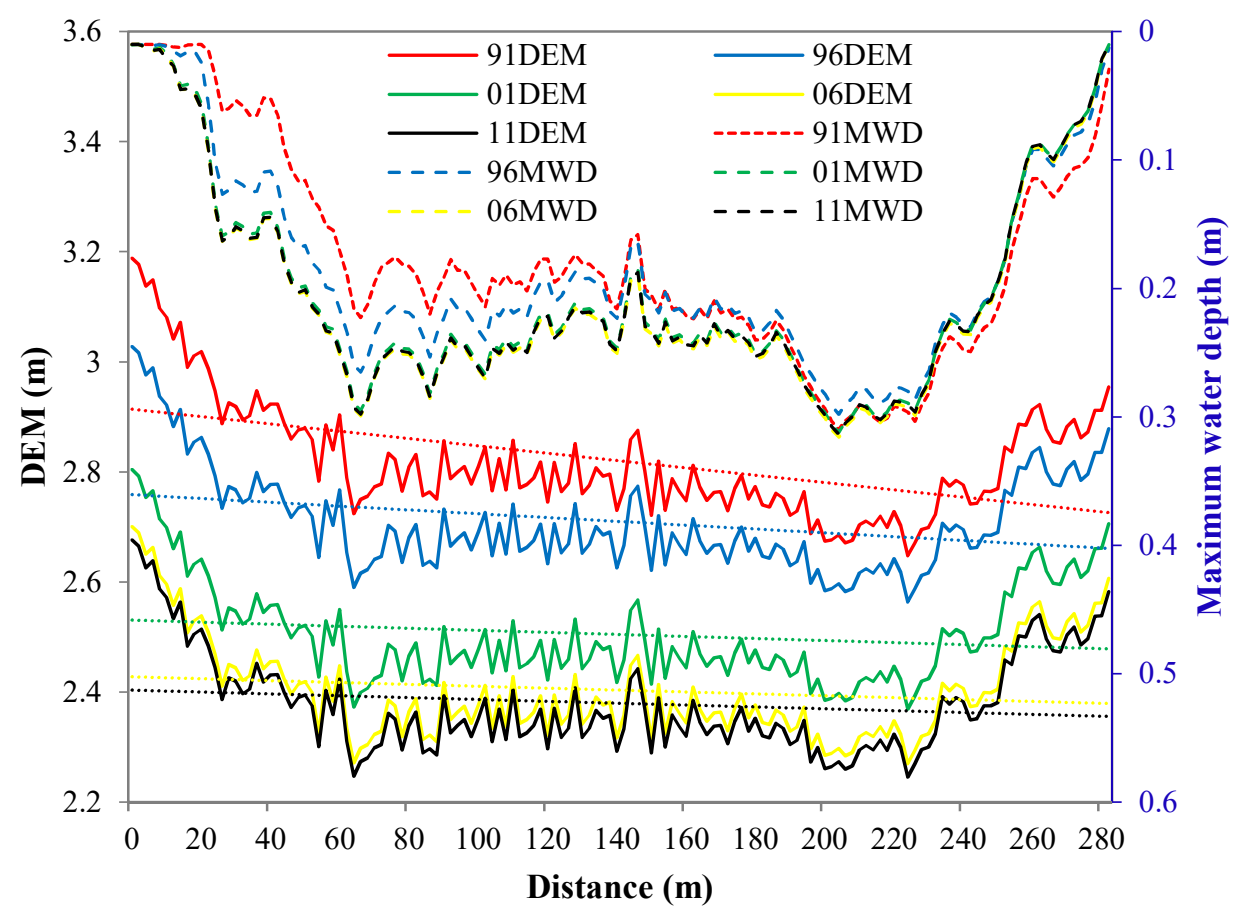

Fig.7 Profiles of ground elevation and maximum water depth (MWDs) along the black boxed road in Fig.6. The straight dotted lines represent the trend lines for various road profiles, the right axis scale (in blue) was inverted to better show MWD changes in relation to ground elevation profiles at different times (i.e. 1991, 1996, 2001, 2006 and 2011).

Table. 1 The area $\left(\mathrm{m}^{2}\right.$ and percentage of simulation domain) subject to different changes in flood depth $(\mathrm{cm})$

\begin{tabular}{ccccccccc}
\hline \multirow{2}{*}{\begin{tabular}{c} 
Change in \\
water depth \\
\cline { 2 - 8 }$(\mathrm{cm})$
\end{tabular}} & \multicolumn{2}{c}{$1991-1995$} & \multicolumn{2}{c}{$1991-2000$} & \multicolumn{2}{c}{$1991-2005$} & \multicolumn{2}{c}{$1991-2010$} \\
\cline { 2 - 8 } & Area $\left(\mathrm{m}^{2}\right)$ & $\begin{array}{c}\text { Percentage } \\
(\%)\end{array}$ & Area $\left(\mathrm{m}^{2}\right)$ & $\begin{array}{c}\text { Percentage } \\
(\%)\end{array}$ & Area $\left(\mathrm{m}^{2}\right)$ & $\begin{array}{c}\text { Percentage } \\
(\%)\end{array}$ & $\begin{array}{c}\text { Area }\left(\mathrm{m}^{2}\right) \\
\text { Percentage } \\
(\%)\end{array}$ \\
\hline$-5 \sim-3$ & 3704 & 0.11 & 8976 & 0.28 & 11396 & 0.35 & 11024 & 0.34 \\
$-3 \sim-2$ & 21712 & 0.67 & 33940 & 1.04 & 28416 & 0.87 & 27680 & 0.85 \\
$-2 \sim-1$ & 66944 & 2.06 & 68040 & 2.09 & 69812 & 2.15 & 71064 & 2.18 \\
$-1 \sim 1$ & 3110544 & 95.60 & 3062900 & 94.14 & 3053420 & 93.85 & 3050288 & 93.75 \\
$1 \sim 2$ & 28112 & 0.86 & 40728 & 1.25 & 44480 & 1.37 & 47940 & 1.47 \\
$2 \sim 3$ & 6868 & 0.21 & 10448 & 0.32 & 12988 & 0.40 & 13872 & 0.43 \\
$3 \sim 5$ & 4056 & 0.12 & 6396 & 0.20 & 7428 & 0.23 & 8404 & 0.26 \\
$>5$ & 3400 & 0.10 & 4828 & 0.15 & 5472 & 0.17 & 5460 & 0.17 \\
\hline
\end{tabular}

\subsection{Subsidence effect on time series of inundation}

Time series ( 5 minutes interval) of F-statistics and depth RMSD referenced to the corresponding 1991 simulation for each scenario are shown in Fig. 8. These reveal that although the corresponding Fit and RMSD profiles of each simulation display a similar shape and high spatio-temporal agreement when compared with the corresponding 1991 
reference, there are clearly deviations in the predicted inundation extent and depth under different simulations. The impact in terms of inundation extent and depth is generally proportionate to the rate of land subsidence throughout the simulations for each period. The sensitivity and response of both measures to land subsidence can be readily distinguished. However, the temporal differences in F statistics between 2006 and 2011 simulations are less marked due to the relatively slow subsidence rates $(\sim 5 \mathrm{~mm} /$ year) during the period. It is also noted that for the depth RMSD curves, the impact of land subsidence between 2005 and 2010 is predicted to be less than that for 2000 to 2005 . The findings support those in section 3.2 and further suggest that in addition to the rate of land subsidence, the spatial variation in relative topographic relief at a local scale affects the distribution of flooded extent and depth. Although land subsidence continues, the spatial variation diminishes up to 2006 , when the rate of land subsidence begins to stabilize. Topographic variations within the modelled domain become less marked and hence the funnel area is less discernible over time, potentially alleviating the adverse impact arising from land subsidence. Given that the chosen watershed is one of the most severely affected areas by land subsidence in Shanghai, it is expected that similar findings will also hold for other watersheds in the city. However, depending on the relative rate of land subsidence across a watershed, other regions might exhibit dissimilar response patterns.
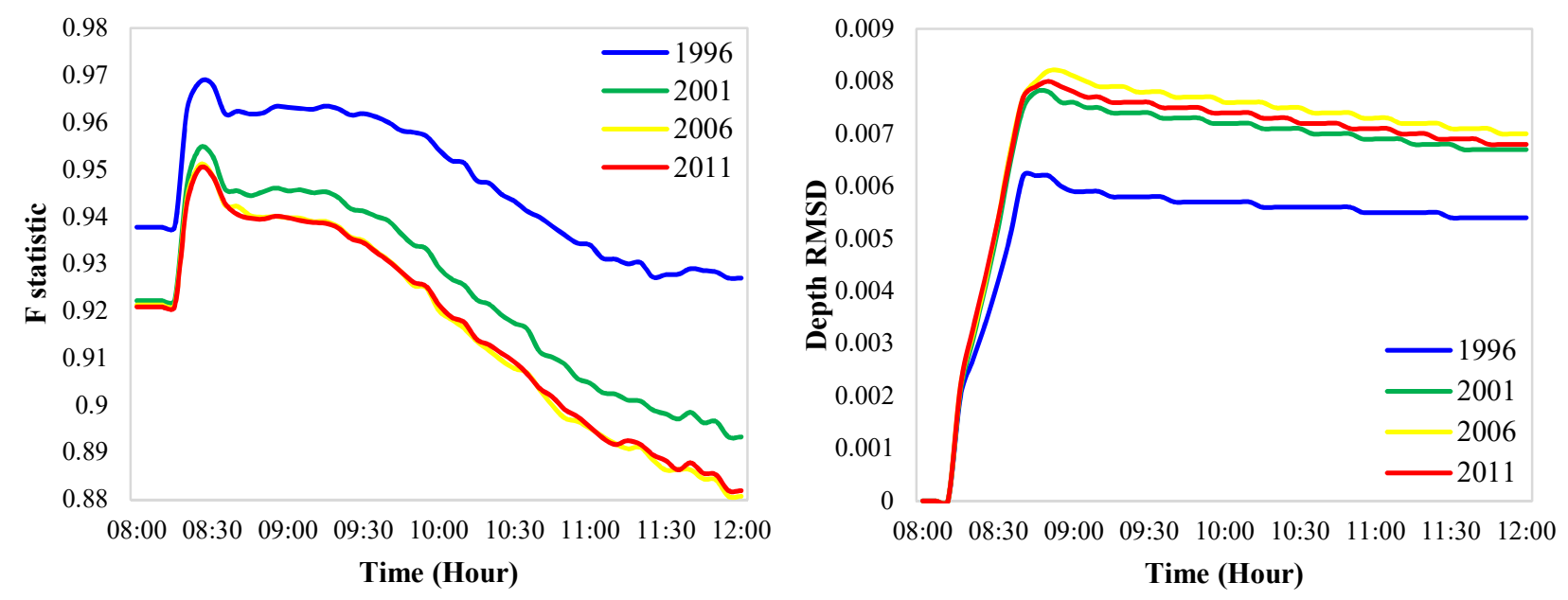

Fig.8 Time series of F statistics and depth RMSD for each period

\subsection{Future perspective and adaptation measures}


Future subsidence in Shanghai is expected to stabilize or slow down due to stricter adaptation measures (Yin et al. 2015b).

According to the land subsidence prevention plan outlined in the Shanghai '12 $2^{\text {th }}$ Five-Year (2011-2015) Plan', the average rate of citywide land subsidence will be stabilized at $6 \mathrm{~mm} / \mathrm{year}$ or lower after 2011 and the development of uneven settlement will be effectively alleviated in the near future by a wide range of management and engineering measures, such as groundwater recharge. For the study area, the reported annual subsidence is even lower than $5 \mathrm{~mm}$ during recent years, which is consistent with the targeted value (Shanghai Geological Environmental Bulletins 2011-2013). Given the control measures, land subsidence is expected to be further alleviated, although uncertainties are inherent in the longer term. This may lead to changes in future flood risks over time.

Flood resilience measures could be implemented to further reduce pluvial flooding due to land subsidence. As the flood response is relatively minor for the majority of subsidence area, appropriate adaptations may only need to be targeted at specific areas with significant changes in relative relief. Several means of adaptation can be addressed individually and/or as an integrated approach in this case, taking into account the increased flood risks due to other factors (such as more intense rainfall). For example, upgrading the drainage system and reduction of impervious area would be the most effective but costly options. In addition, underground spaces (such as garages) could be used as temporary emergency storm water reservoirs in highly affected areas. Finally, low impact measures such as lowering the surface elevation of green open spaces, and construction of green roofs and permeable pavements may be beneficial.

\section{Conclusions}

This paper evaluates the potential impact of land subsidence on pluvial flooding using an urban hydro-inundation model. This is the first attempt to apply high resolution 2D hydraulic modelling to Shanghai for evaluating pluvial flood responses to topographic changes in urban sites, providing detailed insight into the complex interaction between land subsidence, precipitation and changing flood risks. A number of conclusions can be drawn from the results. Overall, land 
subsidence may lead to non-linear, moderate impacts on the spatio-temporal distribution of pluvial flooding (i.e. extent and depth) in high density urban areas. The pluvial flood response to land subsidence essentially involves dynamic storm water routing across a changing landscape. The relative impact mainly depends on the interplay between the watershed-scale distribution of relative subsidence and micro-topographic characteristics at the local scale. In the case of Shanghai, much of the subsiding area shows minor to moderate changes $(<5 \mathrm{~cm})$ in water depth and in some parts of the city risk even decreases. Larger land subsidence effects can only be found at specific-sites with significant focusing of water and/or changes in relative relief. However, it must be noted that the findings from this study are likely to be site-specific. The response of surface water flooding to land subsidence might be different for sites with different topographic characteristics, especially where the terrain is more sloped.

The analysis improves understanding of the relationship between evolving land subsidence and changing pluvial flood, and thus helps to support decision-making in sustainable flood risk management and land subsidence control for subsiding cities. However, to fully understand the impacts, further research is needed to: 1) investigate the sensitivity of our findings to different rainfall events (magnitude, temporal and spatial distribution of amounts); 2) couple 1D sewer flow (surcharging) with 2D overland flow modelling; 3) consider possible subsidence-induced damage or malfunction of drainage system; 4) concentrate on further evaluating the impact of land subsidence using different model domains; and 5) more case studies could be undertaken in different urban environments with more complete subsidence datasets. Finally, further work is needed to include adaptation modelling and assessment. This will allow decision makers to prioritize adaptation investment in terms of site selection and portfolio of measures applied.

Acknowledgments This research was supported by the National Natural Science Foundation in China (Grant No: 41201550, 41371493, 71373084), the Humanities and Social Science Project of Education Ministry (Grant No: 12YJCZH257), Innovation Program of Shanghai Municipal Education Commission (Grant No: 13YZ061, 13ZZ035), the Open Research Fund of State Key Laboratory of Estuarine and Coastal Research (Grant No: SKLEC-KF201407). 


\section{References}

Abidin H, 2005. Suitability of levelling, GPS and INSAR for monitoring land subsidence in urban areas of Indonesia. GIM International, 19: 12-15

Bates P D, De Roo A P J, 2000. A simple raster-based model for flood inundation simulation. Journal of Hydrology, 236 : 54-77.

Bates P D, Horritt M, Fewtrell T, 2010. A simple inertial formulation of the shallow water equations for efficient two-dimensional flood inundation modelling. Journal of Hydrology, 387: 33-45.

Brown S, Nicholls R J, 2015. Subsidence and human influences in mega deltas: The case of the Ganges-Brahmaputra-Meghna. Science of the Total Environment, 527-528: 362-374.

Cabral-Cano E, Dixon T H, Miralles-Wilhelm F, Díaz-Molina O, Sánchez-Zamora O, Carande R, 2008. Space geodetic Imaging of ground subsidence in Mexico City. Geological Society of America Bulletin, 120: 1556-1566.

Calder I R, Harding R J, Rosier P T W, 1983. An objective assessment of soil moisture deficit models. Journal of Hydrology, 60: 329-355.

Chan F, Mitchell G, Adekola O, McDonald A, 2012. Flood risk in Asia's urban mega-deltas drivers, impacts and response. Environment and Urbanization Asia, 3: 41-61.

Dixon T H, Amelung F, Ferretti A, Novali F, Rocca F, Dokka R, Sella G, Kim S W, Wdowinski S. Whitman D, 2006. New Orleans subsidence: rates and spatial variation measured by Permanent Scatterer Interferometry, Nature, 441: 587-588.

Du J K, Qian L, Rui H Y, Zuo T H, Zheng D P, Xu Y P, Xu C Y, 2012. Assessing the effects of urbanization on annual runoff and flood events using an integrated hydrological modeling system for Qinhuai River basin, China. Journal of Hydrology, 464-465: 127-139.

Feng Y, Guo R, Cheng Y, 2007. Research on three dimensional city model reconstruction based on airborne LIDAR. Shanghai Urban Planning Review, 5: 54-57.

Horritt M S, Bates P D, 2001. Effects of spatial resolution on a raster based model of flood flow. Journal of Hydrology, 253: 239-249. IPCC, 2007a. Climate change 2007: The scientific basis. Cambridge University Press, Cambridge.

IPCC, 2007b. Climate change 2007: impacts, adaptation and vulnerability. Cambridge University Press, Cambridge.

Jago-on K, Kaneko S, Fujikura R, Fujiwara A, Imai T, Matsumoto T, Zhang J, Tanikawa H, Tanaka K, Lee B, Taniguchi M, 2009. Urbanization and subsurface environmental issues: An attempt at DPSIR model application in Asian cities. Science of the Total Environment, 407: 3089-3104.

Liu L, Liu Y, Wang X, Yu D, Liu K, Huang H, Hu G, 2015. Developing an effective 2-D urban flood inundation model for city emergency management based on cellular automata. Natural Hazards Earth System Science, 15: 381-391.

Marfai M, King L, 2008. Tidal inundation mapping under enhanced land subsidence in Semarang, Central Java Indonesia. Natural hazards, 44: 93-109.

Osmanoglu B, Dixon T H, Wdowinski S, Cabral-Cano E, Jiang Y, 2011. Mexico City subsidence observed with PS-InSAR, International Journal of Applied Earth Observation and Geoinformation, 13: 1-12.

Pitt M (2008) Learning lessons from the 2007 floods (The Pitt Review). Final report, June 2008. CabinetOffice, London. http://archive.cabinetoffice.gov.uk/pittreview/thepittreview/final_report.html

Sampson C, Fewtrell T, Duncan A, Shaad K, Horritt M, Bates P, 2012. Use of terrestrial laser scanning data to drive decimetric resolution urban inundation models. Advances in Water Resources, 41: 1-17.

Shanghai Municipal Bureau of Planning and Land Resources, 2011-2013. Shanghai geo-logical environmental bulletin 2011-2013. (in Chinese).

Suriya S, Mudgal B V, 2012. Impact of urbanization on flooding: The Thirusoolam sub watershed-A case study. Journal of Hydrology, 412-413: 210-219.

Syvitski J, Kettner A, Overeem I, Hutton E, Hannon M, Brakenridge G, Day J, Vörösmarty C, Saito Y, Giosan L, Nicholls R, 2009. Sinking deltas due to human activities. Nature Geoscience, 2: 681-686.

Waltham T, 2002. Sinking cities. Geology Today, 18: 95-100. 
Wei Z X, Zhai G Y, Yan X X, 2010. Atlas of shanghai urban geology. Beijing, China: Geology Press.

Wu X, Yu D, Chen Z Wilby RL, 2012. An evaluation of land surface modification, storm sewer development, and rainfall variation on waterlogging risk in Shanghai. Natural Hazards, 63: 305-323.

Xu Y, Shen S, Cai Z, Zhou G. 2008. The state of land subsidence and prediction approaches due to groundwater withdrawal in China. Natural Hazards, 45: 123-35.

Yan Y, Doin M P, Lopez-Quiroz P, Tupin F, Fruneau B, Pinel V, Trouve E, 2012. Mexico City subsidence measured by InSAR time series: Joint analysis using PS and SBAS approaches. IEEE Journal of Selected Topics in Applied Earth Observations and Remote Sensing, 5:1312-1326.

Yin J, Yu D, Yin Z, Wang J, Xu S, 2013. Modelling the combined impacts of sea-level rise and land subsidence on storm tides induced flooding of the Huangpu River in Shanghai, China. Climate Change, 119: 919-932.

Yin J, Zhang Q, 2015. A comparison of statistical methods for benchmarking the threshold of daily precipitation extremes in the Shanghai metropolitan area during 1981-2010. Theoretical and Applied Climatology, 120(3): 601-607.

Yin J, Ye M, Yin Z, Xu S, 2015a. A review of advances in urban flood risk analysis over China. Stochastic Environmental Research and Risk Assessment, 29(3): 1063-1070.

Yin J, Yu D, Yin Z, Wang J, Xu S, 2015b. Modelling the anthropogenic impacts on fluvial flood risks in a coastal mega-city: A scenario-based case study in Shanghai, China. Landscape and Urban Planning, 136: 144-155.

Yu D, Coulthard T J, 2015. Evaluating the importance of catchment hydrological parameters for urban surface water flood modelling using a simple hydro-inundation model, Journal of Hydrology 524: 385-400.

Yu D, Lane S N, 2011. Interaction between subgrid-scale resolution, feature representation and grid-scale resolution in flood inundation modelling. Hydrological Processes, 25: 36-53.

Zhou Q, Mikkelsen P S, Halsnæs K, Arnbjerg-Nielsen K, 2012. Framework for economic pluvial flood risk assessment considering climate change effects and adaptation benefits. Journal of Hydrology, 414-415: 539-549. 